\title{
A SHORT CALCULUS PROOF OF JORDAN'S INEQUALITY
}

\author{
NAZRUL HAQUE
}

Theorem 1. If $0<\alpha<\frac{\pi}{2}$, then $\sin \alpha \geq \frac{2 \alpha}{\pi}$.

If $0<\alpha<\frac{\pi}{2}$, then

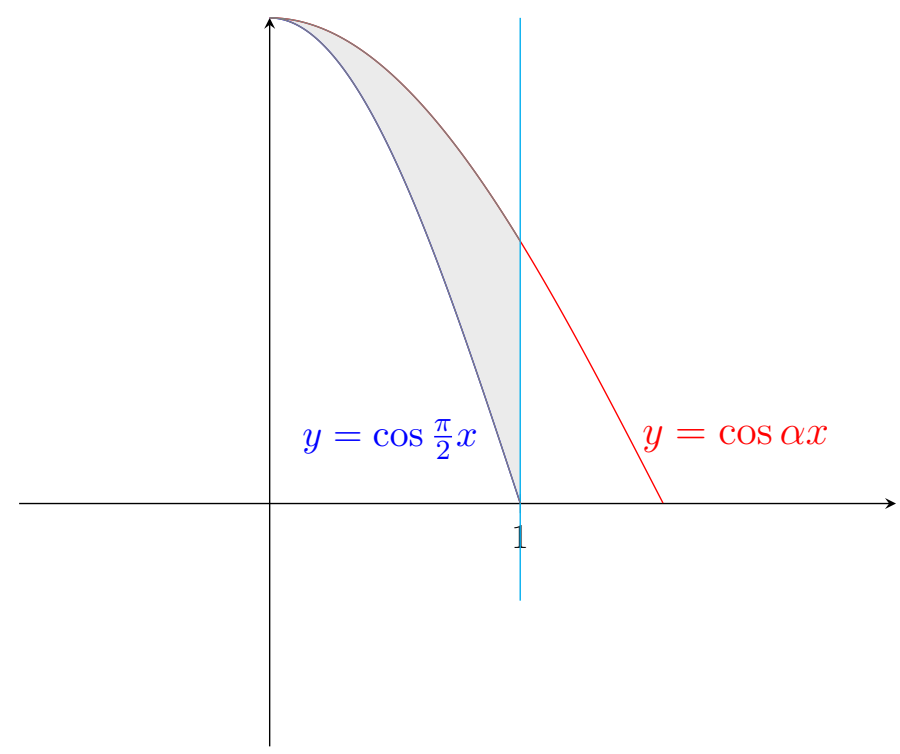

$$
\int_{0}^{1}\left(\cos \alpha x-\cos \frac{\pi x}{2}\right) d x \geq 0 \Longrightarrow \frac{\sin \alpha}{\alpha}-\frac{2}{\pi} \geq 0 \Longrightarrow \sin \alpha \geq \frac{2 \alpha}{\pi}
$$

\section{REFERENCES}

[1] Roger B. Nelsen, Proof without words II, The Mathematical Association of America,, 2000, p. 79.

[2] Nach Feng Yuefeng,Proof Without Words:Jordan's inequality, Mathematics Magazine,Volume 69,no.2,1996,p.126

Department of Mathematics, Ramakrishna Mission Vivekananda Centenary College, Rahara, West Bengal 700 118, INDIA.

Email address: nazrul@rkmvccrahara.org 